\title{
Louis Pasteur (1822-1895)
}

A Paulino Alfonso, homenaje pósfumo.

(Coníerencia dada en Concepción el 26 de Abril de 1924. en las fiestas con que fué inaugurada la Escuela de Medicina).

\section{El hombre}

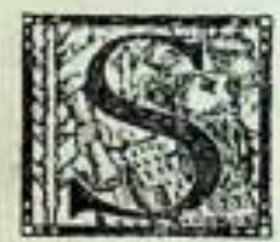

ENTADO en el lecho, la cabeza apoyada sobre la testera, el enfermo se me aparecia envuelto en la penumbra del crepúsculo. Su amplia frente, su blanca barba. su nariz aguileña. se perfilaban borrosamente sobre un fondo obscuro y brillaban como dos chispas inquietas sus ojos, esos ojos negros, de mirada penetrante. como estilete. Hablábamos de Pasteur... este hombre extraordinario me atrae, dije: es un terna de estudio interesante.

Mi vicjo amigo súbito, se incorporó. pasó por su cuerpo enfermo una ráfaga de vida. de pasión: sus ojos brillaron aún más y en son de reproche, contestó: ¿¿cómo. Pasteur un tema? Pasteur es el tema... el tema humano. Pasteur ha solucionado cual ningùn otro hombre los problemas que se presentan al hombre a su paso por la fierra.... y la voz del enfermo. que habia ido subiendo de diapasón. terminó con notas agudas. estando su larga mano descarnada levantada... . Pasteur, joven, sépaselo. es el tema por excelencia..

No volvi a ver a mi viejo amigo. He guardado de esta postrer visita dos impresiones. Una, estética: aquella hermosa cabeza cervantina iluminada por la última luz del dia. se me aparece hoy como un retrato de Rembrandt. de fondo negro, rico en claro-obscuros. lleno de relieve. sembrado de tonalidades doradas. $\mathrm{Y}$ una impresiōn espiritual: Pasteur es el tema, me ha quedado en el oido. provocando en mi repetidas reflexiones...

No volvi a ver a don Paulino Alfonso: pocos días después partía a Viña del Mar y cual ave herida, iba a morir en medio de un matorral de rosas.

Cuando supe su muerte, tomé la resolución. como un homenaje a este intelecto preclaro y a este noble corazón. de penetrar en el misterio del espiritu 
de Pasteur. digo misterio. parque todo lo que es grande es misterioso. y el es. piritu de Pasteur tiene honduras de abismos, resplandores de aurora, agilaciones de tempestad y tranquilidades de desierto.

Si. mi viejo amigo tenia razón. Paslcur es el tema humano por execlencia.

Los profesores Cádiz y Sierra hablaron en la Universidad de Chile del sa. bio: yo tengo encargo del Presidente de esta Universidad de estudiar al hombre

Si se me pidiera indicar desde luego las caracleristicas de esta extraña personalidad, diria que sus lineas cardinales son la inteligencia llevada hasta el genio: la bondad. hasta la santidad laica, y la voluntad. hasta la porfia y el empecinamiento. hasta el sacrificio, hasta el heroismo. Nótese que esta trilogia: La inteligencia, la bondad y la voluntad. forma un todo armónico. forma un conjunto necesario. indispensable para que la personalidad humana sca completa.

Pocos son los hombres en que estas tres cualidades se reunen, aun con intensidad mediana.

La inteligencia es poderosa luz que ilumina el camino de la vida o que, proyectada hacia arriba, hacia el cielo infinito de lo desconocido. permile descubrir. cual estrellas perdidas en la inmensidad de la nada. fenómenos. leyes. que como tesoro. la naturaleza esconde en su seno

La bondad también es luz; pero es luz interior. es lumbre discrela que nos ilumina el alma. que nos conforla, que nos alienta, que nos ilumina en medio de la noche del dolor. de la injusticia, del desengaño...

La inteligencia nos muestra el camino del éxito, sólo de la felicidad material. la bondad nos da la satisfacción inferior. la felicidad complefa y conslante en el triunfo como en la adversidad.

Los jóvenes desestiman la bondad, cuando no la ultrajan con el sarcasmo. y se rinden ante la inteligencia que los fascina.

Al llegar a la madurez de la vida, puedo decir que si me dieran a escoger entre la bondad y la inteligencia. ine quedaría sin trepidar con la primera

Sé que andaria a pasos corlos. que no comprenderia a los hombres y a las cosas. que mi existencia seria humilde y opaca: pero caminaria con la paz en el alma, burlado, pero benévolo, engañado y siempre confiado, marcharia indiferente al mal, haciendo el bien, iluminado por el fuego de la bondad.

El hombre que no ha nacido con esta llama interior tiene un alma obscura. No quiere y no es querido, se siente enemigo de sus semejantes y vive por ello recibiendo un castigo cotidiano. Siente el frio de su corazón y el frio de lo que lo rodea. Es el frio de una muerte en vida. Santa Teresa de Jesús en un grilo de bondad contenido exclama:

Lucifer, iayl, el pobre no quiere.

La voluntad permile realizar lo que la inteligencia concibe y lo que el corazón siente. Sin la voluntad. lo concebido y lo sentido quedan en el reino de lo por hacer y es como si no fueran. Esto explica que si el hombre inteligente y el hombre bueno no son raros. es rarisimo. es excepcional el hombre útil.

Pasteúr. con su inteligencia, abandonó la tierra. voló en el arcano de lo ignoto infinitamente pequeño y volviendo de este vuelo genial, se posó de nuevo 
entre los hombres y por su bondad. cual nuevo Mesias, derramó el bien a caudales. La voluntad férrea le permitió prolongar el esfuerzo de ascensión de su espiritu hasla alcanzar la estrella que su intuición adivinaba.

Pasleur, inteligencia, alma, carácler de excepción, era hijo de obreros por el lado paterno, de campesinos por el lado malerno. Nació. en el año 1822. bajo pobre lecho.

¿Qué consolador es para la juventud humilde ver este árbol genealógico obscuro. que durante generaciones y generaciones ostenta en sus ramas labriegos y labriegos, remalar bruscamente en una flor maravillosal

Al ayer obscuro, puede suceder un mañana luminoso. Del joven depende que esas sombras se truequen en sol radiante.

El bisabuelo era siervo, el biznieto fué magnale ante el cual doblaron la cabeza con respeto y veneración los grandes magnates de la tierra. Napoleón III. en lodo el esplendor de su poderio. se honró con darle hospitalidad en el Castillo de Compiegne: las reinas de Dinamarca y de Grecia lo cortejaban, el Kronprinz de Alemania, el hijo del vencedor de Sedán. faltando a lodo protocolo. se avanzaba hacia él con las manos extendidas anles de serle presentado: un financista, en una enfermedad de Pasteur. le llevó las llaves de su principesca residencia de Bordighera, en el Mediterráneo, para que en ella pasara el invierno.

Pero Séneca lo habia dicho: no hay rey que no sea hijo de esclavo, no hay esclavo que no sea hijo de rey,

El siervo del siglo XVIII tuvo por hijo al rey espiritual del siglo XIX.

Dignos de mencionarse son los antecedentes familiares inmediatos de Pasleur.

Su padre, huérfano a tierna edad. fué soldado de Napoleón e hizo la guerra de España. la campaña de Francia y volvió condecorado a su oficio de obrero curtidor. Era trabajador paciente, de costumbres puritanas, de espiritu lento y reflexivo, taciturno, inclinado a la melancolia. Su madre, hija de jardineros, era muy laboriosa, pero viva, enlusiasta, de imaginación fácil.

Estos caracteres desemejantes, unidos por un mismo fondo de pureza moral $y$ de esfuerzo, formaron un hogar feliz y marcaron honda huella en el hijo predilecto.

Pasteur, en plena gloria, cuando se colocó una placa conmemorativa en su casa nalal, dijo, en su discurso de agradecimiento:

‘Oh! padre mio. $\lceil\mathrm{Oh}$ ! madre mia. ¡Ohl mis queridos desaparecidos. que habéis vivido tan modestamente en esta pequeña casa, a vosotros os debo lodo. Tus entusiasmos. valiente madre mía. los habéis hecho pasar a mi. $\mathrm{Y}$ tú, querido padre mio. cuya vida fué tan ruda como tu rudo oficio. tú me has mostrado lo que puede hacer la paciencia en los largos esfuerzos. A ti te debo la lenacidad en el trabajo cotidiano. No solamente tú tenías las cualidades perseverantes que 
hacen las vidas útiles, pero tú tenias tambièn la admiración de los grandes hombres y de las grandes cosas. Mirar hacia arriba, ir más allá, trafar de levantarse siempre, hé aqui lo que tú me has enseñado. Sed bendecidos uno y otro mis queridos padres, por lo que habéis sido, y dejadme presentaros el homenaje que recibe hoy esta casa.

Esla oración, dicha en plena plaza pública, ante millares de personas es una especie de autoretrato. Aparece en ella bien claro uno de los rasgos que mencionaba en la personalidad de Pasteur, cualidad que apreciaba más que ninguna otra, porque a ella atribuía la mayoria de sus éxitos: la voluntad. Y nos muestra la sensibilidad exquisita, el cariño filial, el amor a los lares, que para él fué una religión. En este mismo discurso, encontramos la frase siguiente: El amor de la ciencia y el culto del hogar, hé aqui las dos grandes cosas que han sido a la vez la pasión y el encanlo de mi vida.

Pero esle hogar feliz vivió siempre en la escasez, con grandes dificultades para proveer a las necesidades más premiosas, y la educación de Dasteur se hizo con sacrificios sin número.

$\mathrm{Y}$ asi son los hogares de muchos hombres ilustres y serán tal vez los hogares de muchos estudiantes que me escuchan: que no renieguen de la pobreza. que no se rebelen contra la adversidad: cuando se presentan en la primavera de la vida. la pobreza es santa y la adversidad es bendita.

Es un fenómeno curioso, en efecto. que el hombre. que la planta humana necesite a veces como el quisco o el espino para crecer. florecer y fruclificar, un suelo duro. una tierra pobre, necesita ser azolada por el viento. necesila conocer el vendaval.

A medida que seguimos a Pasteur. cada nuevo paso nos hace detenernos. porque en cada paso aparece una enseñanza.

Pasteur fué alumno regular, casi mediocre. en todo caso no fué brillante. Esto sorprenderá: pero es explicable. En el periodo de colegio y aun de Universidad se aprecia sobremanera la memoria, y para calificar al alumno, no se juzga ni del raciocinio. ni de la imaginación. ni del equilibrio de las facultades mentales. etc..... para ser alumno brillante, basta saber de corrido lo que está escrito en el libro. y para ello la memoria basta.

A pesar de no ser joven brillante, luego lué distinguido por su carácter serio y trabajador y nombrado, después de su bachillerato, inspector, repetidor. Iba a ganar 300 francos anuales. además de su alojarniento y mantención. Inmediatamente escribia a su casa ofreciendo hacerse cargo de la educación de una de sus hermanas. a quienes aconsejaba como un abuelo. No tenia 18 años cuando les escribia:

.Es mucho, hermanas mías, querer, porque la acción. el trabajo. obedecen - a la voluntad, y casi siempre et trabajo tiene por compañero al éxito. Estas - tres cosas: la voluntad, el trabajo. el éxito, se reparten la existencia humana. - La voluntad abre la puerta a las carreras brillantes y felices. el trabajo la - franquea y una vez llegado al término del viaje, el éxito viene a coronar la - obra.x 
Tal frase merece ser escrita en la primera página de todo libro de estudio: da voluntad abre la puerta, el trabajo la franquea y el tiempo trae el éxito.

Esta idea, adquirida a tan temprana edad, vuelve como un leit-motiv en todos sus escritos.

En esta época hay un incidente en la vida de Pasteur que proyecta viva luz sobre su carácter sentimental.

Fué enviado a Paris a continuar sus estudios; a pesar de su deseo, de su pasión por el estudio, la pena de estar separado de los suyos era más fuerte que lodos sus raciocinios, scuando todo dormía en la pensión y ningún companéro podía verlo u oirlo, repetía en la noche, en sus insomnios, este verso:

1. Cómo la noche parece larga para el dolor que vela!.

La nostalgia, la enfermedad del pais lo invadia: esi pudiera respirar el olor de la curtiduría, decía a un amigo, siento que me curaría. El Director de la pensión comunicó a la familia la tristeza constante de su nuevo pupilo, que amenazaba cambiarse en enfermedad. Un día se avisó al joven pensionista que una visita lo esperaba en un café vecino. Un hombre estaba sentado. la frente escondida en las manos, perdido en sus pensamientos. Era su padre. Eengo a buscarle, le dijo. No hubo más explicaciones. La pena mutua se comprendia (1).

Sólo algunos años después pudo Pasteur tener el valor suficiente para soportar la ausencia de los suyos. En el segundo viaje entró a la Escucla Normal.

Esa sensibilidad tan exquisita, ese cariño filial. fraternal. ese cariño ciego al pais, revelaban ya un fondo de bondad inagolable.

Esta sensibilidad no la perdió con los años y conservó intacto su corazón de niño, y tal vez por eso tuvo para los niños una predilección marcada.

Durante sus estudios de la rabia, cuidaba de mano paternal a los chicos: .cuando me acerco a un niño, decía, me inspira dos sentimientos: el de ternura por el presente, el de respeto por lo que puede ser un día.

Tenía siempre en un cajón de su escritorio una provisión de caramelos y de monedas nuevas, brillantes. Una niñita que atendió largo tiempo de una mordedura de perro rabioso, se entretuvo en perforar las monedas recibidas dia a dia y cuando fué dada de alta se hizo con ellas un collar y corrió a abrazar al grande hombre como lo hubiera hecho con su abuelo (2).

La tentativa de experimentar en el hombre la vacuna anti-rábiga le procuró crueles angustias. La noche de la primera inyección no durmió: lejos de su laboratorio, no teniendo a la vista las experiencias que le daban la certidumbre del éxito, dudaba y volvia como una obsesión la idea de que el niño iba a morir. Mientras duró este primer ensayo, no conoció la paz. Su mujer escribia: smis queridos hijos, otra mala noche para su padre. No se acostumbra a la idea de que está experimentando en un niño. Y sin embargo, hay que hacerlo. Algunos días después, escribe Pasteur, iluminado, a su hijo: smuy buenas noticias del chiquitin

(1) Vallery-Radof.

(2) Vallery-Radot. 
mordido. Espero, pues, con confianza el momento de hacer conclusiones. Mariana hace 31 dias que fué mordido. El niño se salvó. Era el primer caso de curación de la rabia.

Entre los numerosos enfermos que acudian de Francia, de Inglaterra, hasta de Rusia, a consultar a Pasteur. llegó una niñita que había sido mordida hacia cerca de un mes. Se estimó el caso perdido; pero se la sometió al tratamiento pasleuriano. La enfermedad estalló, a pesar de ello. Cuando se acercaba el fin de la pobrecita, Pnsteur pasó lodo el día en casa de la modesta familia. Sentado en la cabecera de la cama, no podía dejarla, La enfermita, entre dos espasmos, le tomaba la mano. Murió. Hubiera deseado tanto salvar a esta chicas, murmuró pasteur, dirigiéndose a la madre, y al salir a la calle, estalló en sollozos.

Pasteur era muy sensible al sufrimiento, donde lo viera: y, asi, exigió que los conejos y perros fueran cloroformados antes de ser sometidos a operaciones experimentales.

Esta sensibilidad era sensibilidad de buena ley, no era emoción enfermiza; era la manifestación de su pureza de alma y de su delicadeza de corazón.

Esta sensibilidad exquisita es atributo de la bondad. El cariño instintivo a los demás, el cariño extendido del círculo de la familia a los amigos, a los conocidos. a los desconocidos, a la humanidad; que hace gozar con la alegria, sufrir con el dolor ajeno, que hace llorar con el que llora, se encuentra sólo en el alma del bueno, que como la cuerda del arpa, está siempre tensa, pronta a vibrar a la menor brisa.

Y este cariño extendido a los hombres y a las cosas se acompaña forzosamente de un olvido de sí mismo. El interés personal pasa a ser algo secundario. a ocupar un segundo plano en la vida, y luego, al poco andar, se olvida. Se vive con los demás y para los demás. Pasteur estaba poseido de un desinterés ab. soluto.

Un día. Napoleón III. maravillado de los resultados prácticos obtenidos por los estudios de Pasteur sobre los vinos. que reportaban a los viñateros varias de cenas de millones de francos al año. le insinuó la conveniencia de hacerse pagar este servicio. Pasteur contestó al soberano:

-En Francia. los sabios creerían desmerecer obrando así,,

Otra anécdota.

Después del desastre del 70 . la administración de Francia, como es fácil comprender, quedó desorganizada, y sus finanzas, en bancarrota.

Pasteur. que vivía de su escaso sueldo de profesor. estaba en una situación critica: sus investigaciones iban a tener que suspenderse. Entonces recibe una ventajosa propuesta de una Universidad italiana. Se le ofrece una Cátedra de Quimica en Pisa; facilidades de trabajo, ambiente de paz y de cordialidad: nada faltaria. Su primer impulso fué rechazar el ofrecimiento: pensaba sólo en su pais vencido: no podía abandonarlo.

Empero. por muy respetables que fueran sus escrúpulos, ¿no era comprender mejor los intereses de su patria ir lejos a sembrar en tierra extraña el pensamiento francés, y nó asistir impotente a su desastre? Estaba indeciso. Para inclinarlo a 
una aceptación, la Universidad de Pisa le prometió ventajas personales, un sueldo de excepción.

Pasteur, entonces, ya no dudó: resolvió quedarse en Francia, y le contestó al Prolesor Chiozza: . Crecria comeler un crimen y mereceria la pena de los desertores si fuera a buscar lejos de'mi patria una posición material mejor que la que ella me puede ofrecer.

Este desinterés, este olvido de sí mismo. lo llevó hasta el heroísmo. como lo veremos más adelante.

Cuando quiso iniciar el estudio de la fiebre amarilla. se le habló del peligro del contagio. ¿Qué importa. contestó Pasteur. la vida en medio del peligro es la verdadera vida. es la gran vida, es la vida del sacrificio, es la vida del ejemplo, es la vida que fecunda.

Si el hombre bueno desea y trabaja por el bien de los demás, tambiên. lógica consecuencia de lo anferior, sobreestima el mérito ajeno, y desestima, olvida el mérito propio. Por eso la modestia es otro atributo de la bondad.

El orgulloso. el vanidoso, al contrario. se coloca secretamente en un pedeslal, y desde toda la altura de su fuero interno, desprecia a sus semejantes e ignora la benevolencia y la justicia.

Pasteur era modesto. No conocía la vanidad. que así como la maleza, crece en las mejores tierras, suele brotar en los espiritus más sanos.

Hablaba de su obra con gran modestia. Es por un trabajo asiduo, decía, sin otro dón particular que el de la perseverancia en el esfuerzo, junto tal vez al atractivo de todo lo que es grande y bello, como he conseguido el éxito en mis investigaciones,

En un Congreso Internacional, en Londres, al entrar Pasteur, reconocido por la asistencia, estalló una larga ovación. mientras se dirigia a su asiento.

Se inclinó hacia su hijo que lo acompañaba. y le dijo: .Es. sin duda, el principe de Gales que llega: deberiamos habernos venido antess. Si es a Ud. a quien todo el mundo aclama., repuso con una sonrisa Sir James Paget, el presidente del Congreso.

Esa misma noche le escribia a su mujer. Estaba bien orgulloso interiormente; no por mi: tú sabes lo que soy ante los triunfos. sino por mi país... mi hijo y mi yerno estaban en la sala. Juzgarás de su emoción.

Se le nombra para el puesto altamente honroso y muy codiciado de Secrelario Perpetuo de la Academia de Ciencias. Antes de aceptar, visita al ilustre quimico Berthelot. y le dice: Estas altas funciones le corresponden más a Ud. que a mi.s

Y Pasteur conservaba esta humildad cristiana cuando se veia glorificado en vida, cuando llegaba él mismo a rebelarse ante las manifestaciones de que era objeto. Asi. decia en una fiesta en su honor: Permitidme que proteste contra este exceso de gloria. Al acordarme un homenaje que sólo se rinde a los muertos ilustres. se adelantan Uds. demasiado ligero al juicio de la posteridad.. 
Este homenaje se le rendia con justicia; se hacia justicia a una serie ininterrumpida de trabajos de consecuencias incalculables para la riqueza pública, para la salud pública: en una palabra, para la humanidad.

Un sabio inglés estimaba que los beneficios recibidos por la industria y la agricultura en Francia eran superiores a la indemnización de guerra de 5 mil millones pagados por ésta a Alemania.

En cuanto a la influencia que tuvo Pasteur sobre la vida humana, también es incalculable. Hay que pensar que sólo después de Pasteur existe la Cirugia y la Higiene, ciencias empíricas que, antes de él, sembraban la muerte por doquiera.

No es mi ánimo entrar al estudio de su obra científica. El tiempo de una conferencia no me permite abordar este vasto tema por ahora.

Recordaré sólo el informe magistral de Paul Bert. presentado a la Cámara de Diputados de Francia cuando el Gobierno solicitó de ésta una recompensa nacional para Pasteur.

-Asi, señores, concluye el relator en su primer informe, los descubrimientos de Pasteur. después de haber iluminado de una luz nueva la obscura cuestión de las fermentaciones y del modo de aparición de los seres microscópicos, han revolucionado ciertas ramas de la industria, de la agricultura, de la patologia. Se queda uno maravillado al ver que tantos resultados, y tan diversos, proceden de un encadenamiento de hechos seguidos, paso a paso. donde nada se ha dejado a la hipotesis, de estudios teóricos sobre la manera cómo el ácido tártrico desvía la luz polarizada.s

Pocos años después, la opinión pública imponía al parlamento una segunda recompensa nacional para el sabio.

De nuevo el diputado Paul Bert es nombrado relator. Exponía en este segundo informe que suna nueva serie de descubrimientos no menos maravillosos desde el punto de vista teórico, y más importante aún desde el punto de vista práctico. habia venido a llenar de sorpresa y de admiración al mundo cientifico. Recapitulados estos trabajos, pueden, decia, ser clasificadas en tres series. y constituyen tres grandes descubrimientos:

- El primero puede ser formulado asi: cada fermentación es el producto del desarrollo de un microbio especial.

-El segundo: cada enfermedad infecciosa es producida por el desarrollo de un microbio especial en el organismo.

-El tercero: el microbio de una enfermedad infecciosa, cultivado en ciertas condiciones determinadas, es atenuado en su actividad nociva; de virus, se ha cambiado en vacuna.,

- Como consecuencia práctica del primer descubrimiento. Pasteur ha dado las reglas de fabricación del vinagre y de la cerveza; ha mostrado cómo se puede preservar el vino y la cerveza contra las fermentaciones secundarias que las echan a perder y se oponen a su conservación y a su transporte.

- Como consecuencia práctica de la segunda. Pasteur ha dado las reglas para poner los rebaños al abrigo de la picada y los gusanos de seda al abrigo de las epidemias que habían arruinado la industria de la sederia. Los cirujanos. 
por otra parte, han llegado, tomando como guia esta segunda fórmula, a hacer desaparecer la erisipela. las infecciones purulentas que antes provocaban la muerte de casi todos los operados.

. Como consecuencias prácticas de la tercera, ha dado reglas para preservar los caballos, los vacunos. los corderos, de la enfermedad carbunclosa que mata cada año en Francia por valor de una veintena de millones de francos. Los porcinos serán resguardados del rouget que los diezma; las aves, del cólera que las concluye. Todo hace esperar que la rabia sea dominada.,

La ley fué votada por la Cámara de Diputados y el Senado por unanimidad, y elevaba la pensión de Pasteur de 12 mil francos a 25 mil francos anuales.

pasteur supo la noticia al leer el diario. en la mañana.

Estos homenajes, este limbo de gloria, estas rosas, iban acompañadas de espinas.

Desde que Pesteur reveló su nombre al mundo cientifico por sus trabajos. cada vez más originales y atrevidos, encontró adversarios, rivales. enemigos que lo acompañaron durante toda su vida como la jauria acompaña desde lejos al ciervo que, veloz, se pierde en la espesura del bosque.

Esta faz de la vida del sabio es doblemente interesante porque, por un lado. nos descubre la pequeñez. la inepcia, la envidia humana que existe latente en toda sociedad, y. por otro, nos descubre la personalidad de Pasteur bajo un aspecto que no sospechábamos.

Se creerá que Pasteur era un hombre manso. pacifico. que sufría el ataque con resignación. Profundo error. Era, al contrario, un hombre impulsivo, combativo, agresivo. Cuando se desconocía la verdad que él mostraba bajo una luz meridiana: cuando se discutia, ignorando lo que se hablaba, cuando se discutía de mala fe, entonces, se transformaba, aparecía el luchador, saltaba a la arena y atacaba con denuedo.

Veámoslo.

En una sesión de la Academia de Ciencias en que dos graves académicos prolongaban un debate a porfía, sin traer a discusión ningún argumento serio y sólo palabras. Pasteur los interrumpió brutalmente: to que le falta a Ud.. señor Fremy, es saber observar. y a Ud., señor Trecul. saber raciocinar,. En una sesión de la Academia de Medicina, terminó una discusión con el Dr. Guerin con estas palabras: estamos solos. en presencia el uno del otro, en este debate; veremos cuál de los dos quedará herido y maltrecho en la lucha.,

Ridiculizó tanto ciertos procedimientos operatorios del Dr. Guerin, que éste. exasperado, dejando su asiento. se precipitó sobre Pasteur. La sesión se levantó en medio del tumulto. Un dia, ha escrito su discípulo el Dr. Roux, en una discusión sobre la fiebre puerperal en la Academia de Medicina, uno de los facultativos más eminentes de la época disertaba elocuentemente sobre las causas de las epidemias en las maternidades. Pasteur se impacientó y le interrumpió con 
brusquedad: so que causa la epidemia no es nada de todo eso. Es el médico y su personal, que transportan el microbio de una mujer enferma a otra mujer sana., Y como el orador contestara que mucho temía que no se encontrase jamás ese microbio. Pasteur se levantó. se dirigió de carrera hacia la pizarra y dibujó la cadenefa del estreptococcus: aqui tenéis su figura.. Y Pasteur decia la verdad: habia dibujado el causante de la muerte de millares y millares de madres. que, efectivamente, el cirujano llevaba de una mujer a otra.

Pero. pasado el momento álgido del debate, volvía la tranquilidad a su espiritu, aun se arrepentia de sus impetuosidades... esta acritud nada tenía de personal: se dirigia a las ideas, nó a las personas.

Tal vez era la pasión del cruzado: nó contra el moro, sino por la cruz.

Pasteur, inflexible, caminaba y hacía siempre más luz; pero. a cada paso. chocaba con obstinados, comparables a extravagantes que cerraran en pleno dia ventanas y cortinas y dijeran: iNo ve que es de nochel. (1).

El Profesor Peter de la Facultad de Medicina decia. hablando del mundo de los microbios: Son curiosidades de historia natural, interesantes, seguramente: pero de poco provecho para la Medicina y que no valen ni el tiempo que sc pierde en ellos ni el ruido que se hace. Nada ha cambiado en Medicina: hay algunos microbios más, ¿qué importa al mundo un microbio más?

Pasteur desistió de ir a la Academia de Medicina: estaba enfermo y cansado de tanta lucha incesante y estëril. Se retiró a pasar el invierno a Bordighera en la Costa Azul. Llegaba hasta él el eco de las discusiones que se prolongaban en la Academia de Medicina. Todas las mañanas queria volverse a Paris a responder a los ataques. Recibía cartas anónimas, artículos injuriosos; todo lo que puede inventar la envidia y la calumnia y que los latinos han tenido razón de confundir en una sola palabra. Aprendió a conocer la vil faz de la naturaleza humana: sno creía que tuviera tantos enemigos. dijo un dia con tristeza este bene. factor de los hombres (1).

Parece incomprensible todo esto.... empero. tiene una explicación y una explicación muy humana: Pasteur fué un revolucionario: sacudió e hizo trizas el viejo edificio dogmático de la Medicina empirica, y levantó desde sus cimientos una nueva, una verdadera ciencia. ¿Cuántos intereses lesionados, cuántas ambiciones frustradas. cuántas emulaciones despertadas?

El sabio que, satisfecho, contento. solemne, habia cerrado los libros y se habia sentado encima de ellos, no perdonaba que se le molestara y se le obligara a abrir de nuevo los libros, a estudiar de nuevo, a borrar como falso lo que él creía verdad y a inscribir como cierto lo que para él era una fantasia, una fantasmagoria.

Hay muchos profesionales del saber que paran su reloj y ya no cuentan las horas del progreso (2).

(1) Vallery-Radot.

(2) Claude-Bernard. 
ILa ciencia se habia detenido en ellos: la ciencia era ellos: ellos la represenlaban en esta tierral

iCómo van a perdonar a Pasteur que les dice: la ciencia se ríe de Uds:: mientras Uds, duermen, ella vuela...: Uds. son simples fetiches de un altar vacío.

En todas partes existen parásitos cientificos, dice Claude Bernard, impolentes para crear nada por ellos mismos, y que se pegan al trabajo de los demás para atacarlos y para tratar así de llamar la atención.

El que ha pasado su vida amarrado a una boya no se conforma que los demás no sean también pontones. El que se ha movido sólo a remolque no comprende que otros se muevan por fuerza propia. El pontón que inerte se cubre de musgo y de conchas, no perdona al transatlántico que airoso pasa a su lado. sin verlo, en demanda de la alla mar. Lo mira al principio con antipatia, y después. con odio.

En todas partes hay seres que no soportan que el mismo hombre sea siempre justo y feliz...

En nuestro pequeño mundo. todos nosotros nos sorprendemos. cada cual en su esfera, al descubrir oposiciones, enemistades, antipatias inmotivadas. Es que, en pequeño, al avanzar. desperlamos lo que despertó. en proporción de su altura $y$ de su potencia. Pasteur.

Mientras mayor es el barco y mayor su velocidad. tanto mayor es la ola que se encabrita en su proa.

Contra Pasteur se levantaron todos los fetiches, todos los pontones, todos los parásilos científicos de Francia.

Si, sí: Pasteur es el tema humano por excelencia.

‘iDe cuântos incidentes fútiles, de luchas estériles, de miserias está atravesada la vida de un grande hombrel Más tarde. no se ve sino la gloria, la apoteosis y las estatuas de la vía pública. Parece que estos semidioses hubieran avanzado como en una avenida triunfal hacia la posteridad reconocida. (1).

He hablado repetidas veces en el curso de esta charla de la voluntad extraordinaria de Pasteur.

Voy a dar de ella un solo ejemplo. Cuando el Gobierno de Francia le encomendó el estudio de la epidemia que diezmaba la crianza de los gusanos de seda. contestó al Ministro: -Vuestra proposición me llena de ansiedad. Considerad. os ruego, que no he tomado nunca un gusano de seda en mis manos.

El Ministro insiste: Pasteur cede y se lanza resuelto a la lucha, abandona su Camilia y va solo al centro agrícola infectado de la región de Alais. Hacia pocas semanas que había iniciado sus estudios. cuando es llamado con urgencia de la casa paterna. Llega al pueblo natal tarde; su padre había muerto.

(1) Vallery-Radot. 
Apenas repuesto del terrible golpe, se dirige taciturno. cabizbajo. al trabajo. Pasan algunas semanas; nuevo golpe. Muere su hija Camila. Pasteur abandona su laboratorio de Alais: parte como un rayo en busca del nido desolado; siente su alma destrozada.... seca sus ojos, echa la cabeza hacia atrás y bamboleante aún, vuelve solo al laboratorio de Alais a continuar los estudios de los gusanos de seda.

Pasan otras semanas. Nuevo golpe. Su mujer, que venía con el resto de la familia a acompañarlo en su destierro, le anuncia que su hija Cecilia se ha enfermado de fiebre tifoidea en la mitad del viaje. Pasteur. lleno el corazón de negros presentimientos, parte a juntarse con los suyos. Llega, y asiste impotente a la marcha de la terrible enfermedad. Su hija Cecilia muere en sus brazos de una hemorragia intestinal. Cuando entra de nuevo a su laboratorio de Alais, exclama: .El trabajo. lahl, afortunadamente tenemos esol, y escribe: héme aquí absorbido de nuevo y por entero en mis estudios; sola distracción en tan grandes dolores.

Pasteur no abandonaba su investigación sobre la enfermedad de los gusanos de seda.

Pero parecía que la fatalidad se ponia por delante de él y le decía: eno pasas. y para ello lo hería una y otra vez en las fibras más delicadas de su alma. En pocos meses habia arrebatado su padre a este hijo. modelo de ternura filial y sus hijos a este padre, modelo de ternura paternal.

Parecia que la naturaleza defendia con empecinamiento el secreto que no quería dejarse arrebatar.

Pasteur iba a recibir un nuevo golpe. Una tarde vió su mente clara y cristalina obscurecerse; densas nubes obscurecieron su vista: sintió su lengua inerte no obedecer a la idea: sintió su mano derecha muerta, y Pasteur cayó fulminado por una hemorragia cerebral.

Vuelto a la vida, a los pocos dias, desde su ́cama, dictaba una nota para la Academia de Ciencias sobre la enfermedad de los gusanos de seda. .Una noche que estaba cerca de él. escribía uno de sus discípulos, traté en vano de distraerlo de sus pensamientos: habiendo perdido la esperanza de disuadirlo. lo dejé desarrollar las nuevas ideas que deseaba hacer conocer. encontrando, no sin sorpresa, que tenía la forma nilida y precisa de todo lo que ha producido: escribí bajo su dictado. sin cambiar una palabra, una nota que leyó el ilustre quimico J. B. Dumas en la Academia de Ciencias el 26 de Octubre de 1868; contenía la indicación de un procedimiento muy ingenioso para descubrir en los primeros ensayos los gusanos de seda predispuestos a la enfermedad.

Tres meses después de este ataque de apoplejía, Pasteur llegaba en camilla a Alais a continuar sus investigaciones sobre los gusanos de seda.

Pasteur demoró cinco años en llegar a la meta. Su voluntad venció al dolor, a la enfermedad y a la muerte.

Debe anotarse, de paso, que los trabajos más transcendentales de Pasteur. especialmente los referentes a las enfermedades de los hombres, son posteriores a su ataque de parálisis, sobrevenido cuando tenía 46 años. 
Analicemos ahora la inteligencia de Pasteur. La inteligencia, esa visión cerebral que permite ver con los ojos del espíritu la realidad, es la resultante de un conjunto de cualidades. En Pasteur, este conjunto tiene cualidades contradictorias que parecen venir de los puntos opuestos del territorio intelectual.

Unir a una observación meticulosa de hechos infimos, aparentemente insignificantes, la imaginación potente, esa loca de la casa que gusta moverse en la irrealidad, unir a la atención sostenida el arranque impetuoso de la fantasía. unir el mélodo, el orden, la disciplina del laboratorista a la indisciplina, al desorden que forzosamente acompaña a la inspiración del poeta, es unir el vuelo del águila que planea soberbia en el azul, dominando el espacio, con la laboriosidad de la hormiga, que va afanada entre las pequeñeces de la tierra.

Así es el espiritu de Pasteur: y ágil, rápido como el rayo, pasa del uno al otro polo, sin perder el equilibrio, sin perder el hilo conductor del pensamiento.

La observación, el raciocinio, el control experimental, he aquí los tres procesos fundamentales de su trabajo cerebral, hé aqui el ciclo que su espíritu recorre incesantemente, con febril actividad.

-Rassamblons des faits pour avoir des ideés, habia dicho Buffon, y repetia siempre Pasteur: nacida la idea al contacto de la realidad observada, dejaba las alas libres a la imaginación, que concebía en lo alto la hipótesis: concebida la hipólesis, volvia inmediatamente a tocar tierra y comprobaba la efectividad o el error de su concepción. Inscrito, demostrado el nuevo hecho adivinado por la imaginación. partía de nuevo, alas desplegadas, en pleno sueño. Observación, adivinación. experimentación. son como tres peldaños que al continuarse uno en pos de otro, forman una escala que a semejanza de la escala de Jacob. lo hace llegar al cielo de lo desconocido.

La ciencia vive, escribia Pasteur, de soluciones sucesivas de por quées más y más sutiles, más y más cercanos a la esencia misma de los fenómenos. .

Dos peldaños firmes en plena realidad, separados por un peldaño en el vacio de la fantasía. Este peldaño misterioso es el que permite elevarse. Con la observación y la experimentación solas, habria quedado a ras de la tierra: con la imaginación sola, habria escalado las nubes, habria hecho obra de poeta. pero nó de sabio.

Y cada una de estas tres lases del trabajo mental lormaban para Pasteur un todo indisoluble, una cadena de tres eslabones que de nada servía si se rompia y se soltaba una argolla.

Al presentarse Pasteur como candidato a la Academia de Ciencias, el relafor de la corporación escribia:

.Ha podido elevarse continuamente, con igual éxito. de la concepción teó- rica a la experimentación que demuestra, y de la demostración misma, a nuevas - vistas especulativas: de manera que la inducción lógica y la observación ma- terial se sirven una en pos de ofra, por un encadenamiento continuo de coro- lario y verificación..

J. B. Dumas, uno de sus maestros, dirigia las siguientes palabras a la Aca- 
demia de Ciencias, en la sesión dada en honor de Pasteur: .Tiene el equilibrio admirable de la inteligencia que observa. del genio que adivina y de la mano que ejecuta.

Otra particularidad y muy importante del espiritu de este sabio es su poder de concentración del pensamiento, trátese de meditar o de observar, en un punto. en un tema dado.

Cumplia el axioma de la estrategia moderna, la concentración del fuego en un momento dado en un solo punto del campo de batalla.

- Cuando se batía contra el misterio del infinito, cuando creía entrever una luz en la noche de las cosas, cuando estaba sobre la pista de una verdad dificil de alcanzar. quedaba como aislado del mundo exterior: mientras estaba en esta especie de crisis, no hablaba, no existía para los suyos. (1).

A veces Madame Pasteur. bajaba de su departamento al laboratorio, en su ausencia. e interrogaba a sus alumnos: «qqué otra novedad tenemos?... preguntaba ansiosa la mujer... porque hace un mes que no pronuncia palabra..

Tu padre. escribía ella misma a su hijo, siempre preocupado, habla poco. duerme poco, se levanta con el sol. en una palabra, continúa la vida que he empezado con él hace 35 años.,

Su pensamiento, tenaz, porfiado, narra uno de los lestigos de su vida. amigo y discípulo, el Dr. Roux, atacaba las dificultades y concluia por resolverlas, como la llama del soplete constantemente dirigida contra un cuerpo refractario concluye por fundirlo,

Y Pasteur, a su vez, confesaba, al mirar con cariño el resultado de una investigación: Es increible tanta nitidez, tanta precisión ahora que está terminado. porque estos resultados tan simples me han hecho pasar muchas malas noches.

Pero cuando el enigma estaba descifrado cuando Pasteur volvía con su espiritu en medio de los suyos, su boca contraída por la meditación tomaba una suavidad de niño, sus ojos absorbidos y perdidos se iluminaban de alegre bondad (1).

Pasteur descansaba su espiritu de la tensión sostenida a que lo obligaba la ciencia. en el solaz que procura la belleza. especialmente la belleza literaria. No comprendia a los sabios que hacian alarde de insensibilidad estética: no por ser menos literatos son más sabios, pensaba con malicia.

Sin haber sido un profesional de las letras, por los trozos que han oido. habrán comprendido Uds. que había en él todo el paño del gran escritor. Profundidad del pensamiento, belleza de la forma. La frase concisa, cargada de idea se desenvuelve majestuosa y, sin embargo, ligera; elegante y, sin embargo, sobria.

No era tampoco insensible a las artes plásticas: pero no las cultivó. Nos ha dejado una bella colección de pasteles hechos en la juventud, una galería de sus queridos desaparecidos.

(1) Lumet. 
Nos detendremos más en la filosofia de Pasteur.

Su filosofia era simple. sentimental; no era de esas filosofias sutiles y abstractas, tan sutiles y tan abstractas que a fuerza de sutileza y abstracción, se pierden en la neblina de la incomprensión.

Oigámoslo:

- Mi filosofia es toda del corazón y nada del espiritu, y me abandono. por ejemplo, a la que inspira estos sentimientos tan naturalmente eternos que uno siente a la cabecera del hijo que se ha querido y del cual se ve escapar el último soplo. En este momento supremo, hay algo en el fondo del alma que nos dice que el mundo podria bien no ser un puro conjunto de fenómenos propios de un equilibrio mecánico. un mundo salido del caos de los elementos por el simple efecto del juego gradual de las fuerzas de la materia. iYo admiro a todos nuestros grandes filósofos! Tenemos, los hombres de ciencia, la experiencia que corrige y modifica sin cesar nuestras ideas y vemos constantemente que la naturaleza, en la menor de sus manifestaciones, está hecha de otra manera que la que habiamos presentido. Y ellos, los filósofos, que adivinan siempre. colocados como están detrás de ese velo tupido del principio y fin de todas las cosas. ¿cómo hacen, pues, para saber?...

Y en otra ocasión, escribia:

- En cada uno de nosotros hay dos hombres: el sabio que hace tabla rasa. - que por la observación. la experimentación y el raciocinio quiere elevarse al - conocimiento de la naturaleza. y al lado. el hombre sensible. el hombre de - Iradición, de fe o de duda, el hombre de sentimiento, el hombre que llora sus - hijos que ya no son, que no puede layl probar que los volverá a ver. pero - que lo cree y lo espera, que no quiere morir como muere un microbio... Los - dos dominios son distintos: y desgraciado el que pretende hacerlos coincidir. - en el estado imperfecto de nuestros conocimientos humanos.s

En su discurso de recepción en la Academia Francesa, vuclve a abordar el tema del más allá en una página que quedará como un trozo de literatura clásica. No resisto a la tentación de leerla. ¿¿No estará siempre en el destino del - hombre el de preguntarse que hay más allá? ¿Qué hay más allá? El espiritu - humano. empujado por una fuerza invencible, no cesará jamás de preguntár- selo. ¿Qué hay más allá? ¿Cómo detenerse en el tiempo o en el espacio? Ya - que el punto en el cual el pensador se detiene posee un tamaño finito. más - grande sólo que todos los que lo han precedido. en cuanto principia a con- siderarlo, vuelve implacable la pregunta, y sin que pueda ahogar el grifo de - su curiosidad. Es inútil contestar: más allá son espacios. tiempos. tamaños sin - limite. Nadie comprende estas palabras. El que proclama la existencia del infinito. - y nadie se escapa de ello, acumula en esta afirmación más sobrenatural que el - que hay en todos los milagros de todas las religiones: porque la noción del - infinito tiene este doble carácter: de imponerse y ser incomprensible. Cuan- do esta noción se apodera del espíritu, no hay más que inclinarse. Todavia. - en eslos momentos de angustia profunda. hay que pedirle gracias a la razón: 
- todos los resortes de la vida intelectual amenazan relajarse; se siente uno cer- ca de la sublime locura de Pascal. iLa noción del infinito en el mundol Veo - en todas partes su expresión. Por ella. el sobrenatural está en el fondo de - todos los corazones. La idea de Dios es una forma de la idea del infinito. - Mientras el misterio del infinito pese sobre el pensamiento humano. templos - serán elevados al culto del infinito. Que Dios se llame Brahma. Alláh, Jehová - o Jesús. Y sobre el piso de csos templos. se verán hombres arrodillados. - prosternados, anonadados en el pensamiento del infinito.

He querido hacer revivir ante Uds. a este hombre extraordinario. Mi trabajo ha sido muy imperfecto, pero, a pesar de tanta imperfección, creo haber hecho una obra útil.

Es útil ver y sentir durante algunos instantes la vecindad de una mente genial y de un alma de excepción. Se vuelve de este contacto. es cierlo, abatido. deprimido: pero. al mismo tiempo. nace de las profundidades de nuestro ser un soplo saludable de reacción, un impulso irresistible de elevarse, de perfeccionarse, de engrandecerse.

Quisiera que los estudiantes que me escuchan no olvidaran en sus estudios y después, en su vida, a este espiritu superior: quisiera que la nueva Escuela de Medicina de Concepción le diera su nombre a alguna sala, a algún anfiteatro. a algún laboratorio. y que el mármol con el nombre de Pasteur fuera como el sello del juramento que profesores y alumnos harán de inspirarse siempre en la huella luminosa dejada por el maestro a su paso por la tierra.

Quisiera decirles a los estudiantes de Medicina lo que les diria Pasteur. si estuviese entre nosotros: les diria lo que les dijo a ofros estudiantes, que como Uds. lo admiraban: Vivid, les diría, en la paz serena de los laboratorios y de las bibliotecas;. Preguntaos: ¿¿qué he hecho por mi instrucción?. En seguida, a medida que avancéis: - ¿qué he hecho por mi pais?. Hasta el momento en que tengáis esa inmensa felicidad de pensar que habéis contribuido en algo al progreso y al bienestar de la humanidad, y cuando os acerquéis a la gran meta, debéis tener el derecho de deciros: He hecho lo que he podido.

Leí la vida de Pasteur a la orilla del mar; cuando levantaba los ojos del libro. encontraba cierta similitud entre lo que mi espiritu meditaba y lo que mi vista abarcaba.

Las olas, que en incansable carrera azotaban la arena, ¿no eran, acaso. la expresión de aquella voluntad que, incansable, golpeaba y golpeaba a la puerta de lo ignoto?: la blanca espuma que se extendia rifmicamente sobre la playa. ¿no era el símbolo de aquella alma pura que, inagotable. derramaba bienes sobre la tierra?; aquellas rocas que se avanzaban, una tras otra. desgarrando la 
ola pujante en su avance, me aparecian como esos espiritus forcidos que a cada paso que Pasteur avanzaba en el misterio, lo atacaban. lo vilipendiaban. lo calumniaban. Pero la ola pasaba y los dejaba ocultos bajo su magnifico manto.

Esa orgia de luz, esos mil reflejos brillantes. esa lluvia de plata que desparramaba el sol sobre el abismo obscuro de las aguas, se me figuraba la luminosidad solar con que inundó Pasteur el abismo de la vida orgánica, la obscuridad de la Medicina empirica de entonces.

$\mathrm{Y}$ en fin, ese horizonte infinito que como una línea separa el cielo del mar. no era más extenso que el horizonte cientifico infinito revelado por Pasteur a los hombres.

DR. CARLOS CHARLIN CORREA,

Algarrobo, 7 de Marzo de 1924. 